\title{
PENGATURAN LED MELALUI PORT PARALEL MENGGUNAKAN PEMROGRAMAN VISUAL
}

\author{
Heri Mulyono \\ Dosen Pendidikan Informatika, STKIP PGRI Sumbar \\ herimulyonoaja@gmail.com
}

\begin{abstract}
ABSTRAK
Port parallel yang terdapat pada komputer dapat digunakan untuk mengendalikan suatu peralatan elektronik, seperti lampu, kipas angin, pendingin ruangan dan lain-lain. Pada rancangan ini penulis membuat rangkaian LED yang dihubungkan melalui antar muka (interface) port paralel dan membuat program aplikasi untuk pengaturannya. Hasil pengujian ini dapat disimpulkan bahwa port paralel mempunyai 3 macam register yaitu register data, status, dan kontrol. Untuk menggunakan register yang ada, dibutuhkan pemahaman sesuai dengan sifat registernya. Register Data bersifat dua arah (bi-directional), sehingga dalam penggunaannya dapat diprogram sebagai input dan output. Register Status hanya dapat digunakan sebagai input saja. Sedangkan sifat register control adalah hanya satu arah dan memiliki sifat Normal dan Terbalik pada bit-bit tertentu.
\end{abstract}

Key word; port parallel, register data.

\section{PENDAHULUAN}

\subsection{Latar Belakang}

Dalam kehidupan sehari-hari dapat kita temui benda berupa lampu-lampu yang bergerak secara beraturan dan bervariasi dengan kombinasi warnawarni. Hal ini terkadang dapat menambah keindahan tersendiri bagi penikmatnya, terutama bagi kita yang memiliki jiwa seni. Lampu-lampu tersebut biasanya digunakan sebagai hiasan atau aksesoris pada taman kota, gedung-gedung dan lain-lain yang semua itu dapat menambah nilai keindahan. Untuk membuat lampulampu yang bergerak tersebut, mungkin sulit bagi orang awam, tetapi merupakan suatu hal biasa bahkan mudah bagi seseorang yang memiliki keahlian atau keterampilan di bidang elektronika dan computer.

Walaupun saat ini telah banyak
yang membuat rangkaian lampu
berjalan (Running LED)
berbagai teknik, namun pada
kesempatan ini, penulis akan mencoba
menguraikan bagaimana cara membuat
lampu bergerak (hidup/ mati)
menggunakan computer melalui port
parallel.

\section{PEMBAHASAN}

\section{Port Paralel}

Port Paralel merupakan saluran/ port yang disediakan sebagai interface antara komputer dengan printer era 90an hingga tahun 2000. Namun demikian kita masih bisa menggunakannya untuk membuat 
projek-projek atau alat-alat yang dikendalikan menggunakan komputer. Kemudahan pemrograman menggunakan Port Paralel membuat port ini semakin populer di kalangan para hobis. Port Paralel juga dapat digunakan untuk pengendalian, misalnya, robot yang dikendalikan komputer, pemrogram mikrokontroler
Atmel atau PIC, otomasi rumah, dan lain-lain. Port paralel ini terhubung dengan dunia luar melalui konektor DB25, yang terbagi atas tiga kelompok register, yaitu: Register Data(D7..D0), Register Status (S7..S0), dan Register Control(C7..C0). Berikut adalah table yang menjelaskan sifat-sifat dari ketiga register tersebut:

\begin{tabular}{|c|l|c|c|c|}
\hline No.Pin & Sama Sinyal & Arah & Register-Bit & Sifat \\
\hline 1 & 'Strobe & Out & Co & Terbalik \\
\hline 2 & Data0 & In/Out & Do & Normal \\
\hline 3 & Data1 & In/Out & D1 & Normal \\
\hline 4 & Data2 & In/Out & D2 & Normal \\
\hline 5 & Data3 & In/Out & D3 & Normal \\
\hline 6 & Data4 & In/Out & D4 & Normal \\
\hline 7 & Data5 & In/Out & D5 & Normal \\
\hline 8 & Data6 & In/Out & D6 & Normal \\
\hline 9 & Data7 & In/Out & D7 & Normal \\
\hline 10 & 'Ack & In & S6 & Normal \\
\hline 11 & Busy & In & S7 & Terbalik \\
\hline 12 & Paper-Out & In & S5 & Normal \\
\hline 13 & Select & In & S4 & Normal \\
\hline 14 & Line feed & Out & C1 & Terbalik \\
\hline 15 & 'Error & In & S3 & Normal \\
\hline No.Pin & Sama Sinyal & Arah & Register-Bit & Sifat \\
\hline 16 & 'Initialize & Out & C2 & Normal \\
\hline 17 & 'Select Printer & Out & C3 & Terbalik \\
\hline $18-25$ & Ground & - & - & - \\
\hline
\end{tabular}

Pembagian register dan penggunaan pin ditunjukkan seperti pada Gambar 1, sedangkan rangkaian yang digunakan untuk pengujian ditunjukkan pada Gambar 2. Perlu mendapat perhatian bahwa penggunaan DIP Siwtch hanya sebagian saja, menyesuaikan dengan bit-bit pada Register Status yang digunakan. Pada Tabel 2 ditunjukkan koneksi antara LED, DIP Switch dan konektor DB25. 
Penelitian Bidang Komputer Sains dan Pendidikan Informatika V1.i2(48-54)

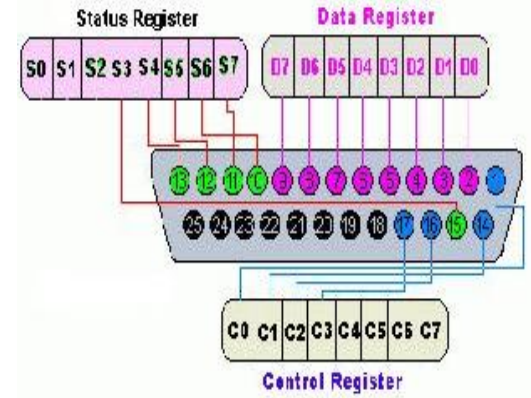

Gambar 1

Tabel 2

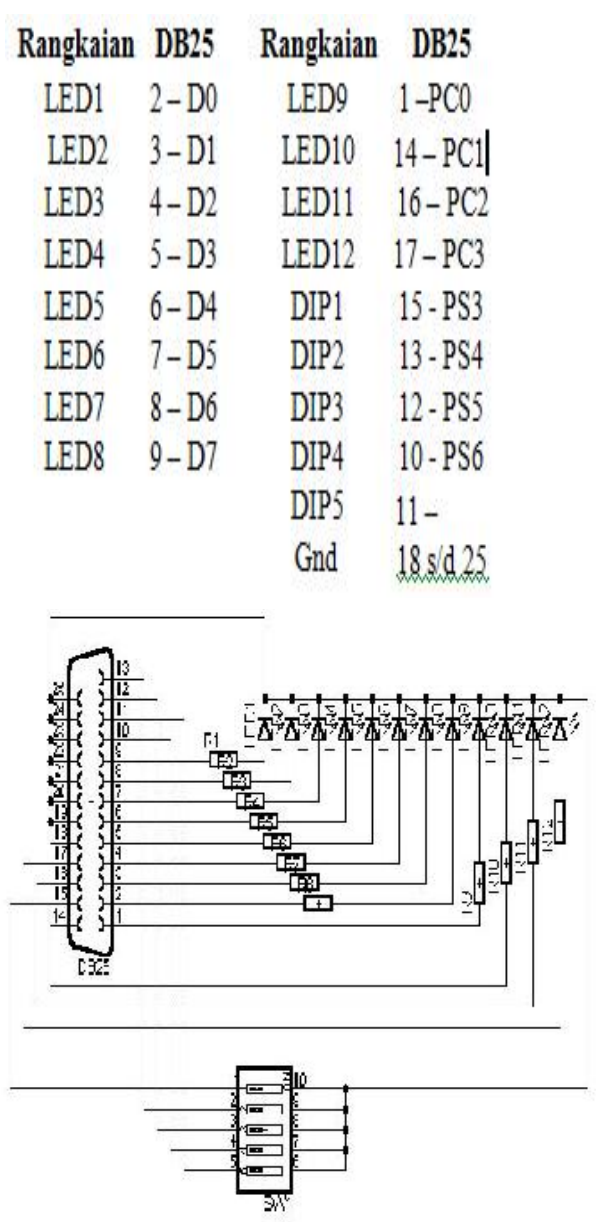

Gambar 2

\section{Program Visual Basic}

Setelah perangkat keras (rangkaian) telah selesai dibuat, langkah selanjutnya adalah membuat program komputer untuk mengatur hidup atau matinya LED sesuai dengan yang diinginkan dengan cara memberi tanda checklist.

\section{a. Merancang Form}

Langkah pertama dalam membuat program visual adalah merancang form. Berikut adalah contoh rancangannya:

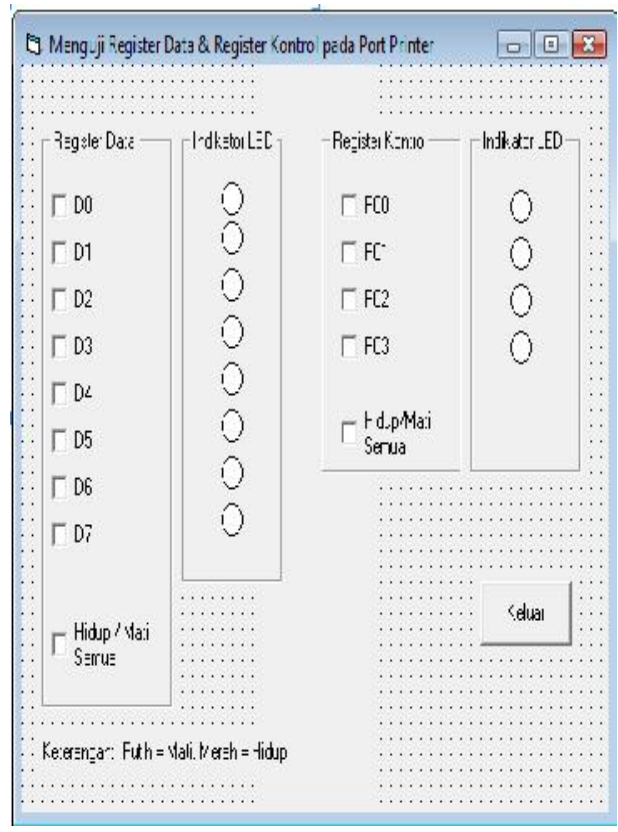

b. Tulis Coding program

Klik 2x pada D0, dan tuliskan program sebagai berikut:

Private Sub Check1_Click()

Dim tmp As Byte

tmp $=$ PortIn $(\& H 378)$

If Check1.Value $=1$ Then

PortOut \&h378,tmp or \&h1 
Penelitian Bidang Komputer Sains dan Pendidikan Informatika

Shape1.BackColor $=$ vbRed

Else

PortOut \&h378, tmp and $\& h F E$

Shape1.BackColor =
vbWhite
End If
End Sub

Untuk D1 s/d D7 lakukan perubahan seperti pada table berikut :

\begin{tabular}{|c|l|l|}
\hline Komponen & \multicolumn{1}{|c|}{ Value =1 } & \multicolumn{1}{c|}{ Else } \\
\hline Check2 (D1) & $\begin{array}{l}\text { PortOut \&h378, tmp or \&h2 } \\
\text { Shape2.BackColor = vbRed }\end{array}$ & $\begin{array}{l}\text { PortOut \&h378, tmp and \&hFD } \\
\text { Shape2.BackColor = vbWhite }\end{array}$ \\
\hline Check3 (D2) & $\begin{array}{l}\text { PortOut \&h378, tmp or \&h4 } \\
\text { Shape3.BackColor = vbRed }\end{array}$ & $\begin{array}{l}\text { PortOut \&h378, tmp and \&hFB } \\
\text { Shape3.BackColor = vbWhite }\end{array}$ \\
\hline Check4 (D3) & $\begin{array}{l}\text { PortOut \&h378, tmp or \&h8 } \\
\text { Shape4.BackColor = vbRed }\end{array}$ & $\begin{array}{l}\text { PortOut \&h378, tmp and \&hF7 } \\
\text { Shape4.BackColor = vbWhite }\end{array}$ \\
\hline Check5 (D4) & $\begin{array}{l}\text { PortOut \&h378, tmp or \&h10 } \\
\text { Shape5.BackColor = vbRed }\end{array}$ & $\begin{array}{l}\text { PortOut \&h378, tmp and \&hEF } \\
\text { Shape5.BackColor = vbWhite }\end{array}$ \\
\hline Check6 (D5) & $\begin{array}{l}\text { PortOut \&h378, tmp or \&h20 } \\
\text { Shape6.BackColor = vbRed }\end{array}$ & $\begin{array}{l}\text { PortOut \&h378, tmp and \&hDF } \\
\text { Shape6.BackColor = vbWhite }\end{array}$ \\
\hline Check7 (D6) & $\begin{array}{l}\text { PortOut \&h378, tmp or \&h40 } \\
\text { Shape7.BackColor = vbRed }\end{array}$ & $\begin{array}{l}\text { PortOut \&h378, tmp and \&hBF } \\
\text { Shape7.BackColor = vbWhite }\end{array}$ \\
\hline Check8 (D7) & $\begin{array}{l}\text { PortOut \&h378, tmp or \&h80 } \\
\text { Shape8.BackColor = vbRed }\end{array}$ & $\begin{array}{l}\text { PortOut \&h378, tmp and \&hDF } \\
\text { Shape8.BackColor = vbWhite }\end{array}$ \\
\hline
\end{tabular}

Dan Klik 2x pada komponen Check13 (Hidup/Mati Semua), tuliskan coding program seperti berikut:

Private Sub Check13_Click()

If Check13. Value $=1$ Then

'PortOut \&h378,tmp or \&hFF

Check1. Value $=1$

Check2. Value $=1$

Check3. Value $=1$

Check4. Value $=1$

Check5.Value $=1$

Check6. Value $=1$

Check7. Value $=1$

Check8. Value $=1$

Shape1.BackColor $=$ vbRed

Shape2. BackColor $=$ vbRed

Shape 3. BackColor $=$ vbRed

Shape4.BackColor $=$ vbRed

Shape5.BackColor $=$ vbRed

Shape6.BackColor $=$ vbRed
Shape7.BackColor $=$ vbRed

Shape8.BackColor $=$ vbRed

Else

'PortOut \&h378,tmp and \&h0

Check1. Value $=0$

Check2. Value $=0$

Check3. Value $=0$

Check4. Value $=0$

Check5. Value $=0$

Check6. Value $=0$

Check7. Value $=0$

Check8. Value $=0$

Shape 1. BackColor $=$ vbWhite

Shape2. BackColor $=$ vbWhite

Shape3. BackColor $=$ vbWhite

Shape4.BackColor $=$ vbWhite

Shape 5. BackColor $=$ vbWhite

Shape6.BackColor $=$ vbWhite

Shape 7.BackColor $=$ vbWhite

Shape8.BackColor $=$ vbWhite

51 Diterbitkan Oleh Program Studi Pendidikan Informatika STKIP PGRI Sumbar 
End If

End Sub

Klik 2x pada komponen Check9(PC0), tuliskan coding program berikut:

Private Sub Check9_Click()

Dim tmp As Byte

'tmp $=\operatorname{PortIn}(\& \mathrm{H} 37 \mathrm{~A})$

If Check9.Value $=0$ Then

'PortOut \&h37A,tmp or \&h1

Shape9. BackColor $=$ vbRed

Else

'PortOut \&h37A,tmp and \&hFe

Shape9. BackColor $=$ vbWhite

End If

End Sub

Klik 2x pada komponen Check10(PC1), tuliskan coding program berikut:

Private Sub Check10_Click()

Dim tmp As Byte

'tmp = PortIn $(\& \mathrm{H} 37 \mathrm{~A})$

If Check10. Value $=0$ Then

'PortOut \&h37A,tmp or \&h2

Shape10.BackColor $=$ vbRed

Else

'PortOut \&h37A,tmp and \&hFd

Shape 10. BackColor $=$ vbWhite

End If

End Sub

Klik 2x pada komponen

Check11(PC2), tuliskan coding program berikut:

Private Sub Check11_Click()

Dim tmp As Byte

'tmp $=$ PortIn(\&H37A)

If Check11. Value = 1 Then

'PortOut \&h37A,tmp or \&h4

Shape11.BackColor $=$ vbRed

Else
'PortOut \&h37A,tmp and \&hFB

Shape11.BackColor $=$ vbWhite

End If

End Sub

Klik 2x pada komponen Check12(PC3), tuliskan coding program berikut:

Private Sub Check12_Click()

Dim tmp As Byte

'tmp = PortIn (\&H37A $)$

If Check12. Value $=0$ Then

'PortOut \&h37A,tmp or \&h8

Shape12.BackColor $=$ vbRed

Else

'PortOut \&h37A,tmp and \&hF7

Shape12.BackColor $=$ vbWhite

End If

End Sub

c. Jalankan Program

Jika program telah benar, maka hasilnya dapat dilihat pada rangkaian LED, dan LED akan hidup saat tombol checklist diaktifkan (enabled) dan sebaliknya LED akan mati ketika tombol checklist dihilangkan (dissabled). Hasil program juga dapat dilihat pada layar monitor dengan memperhatikan kode warna, jika merah berarti mewakili LED hidup, dan putih mewakili LED mati seperti gambar3a s/d 3d berikut:

52 Diterbitkan Oleh Program Studi Pendidikan Informatika STKIP PGRI Sumbar 
Penelitian Bidang Komputer Sains dan Pendidikan Informatika

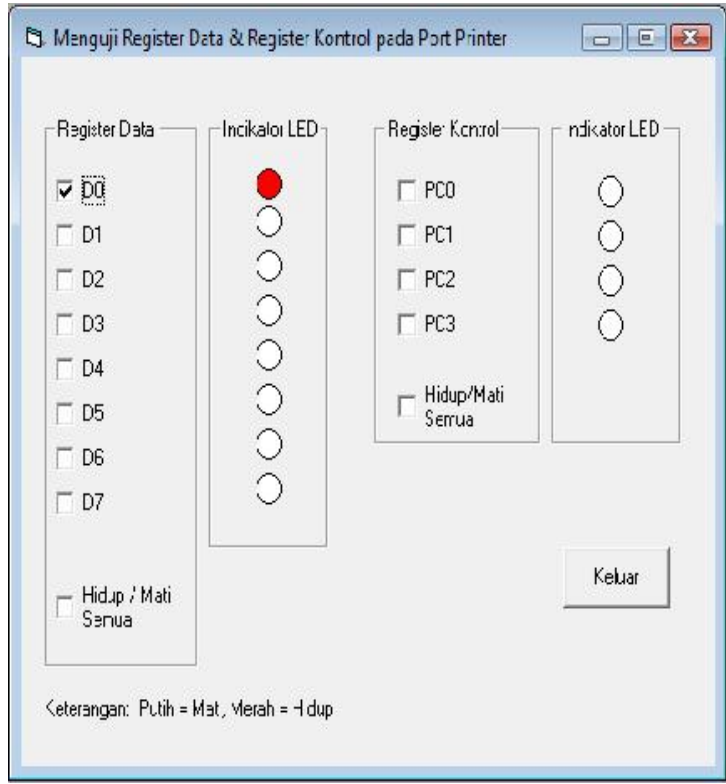

Gambar 3a. Menghidupkan LED 1

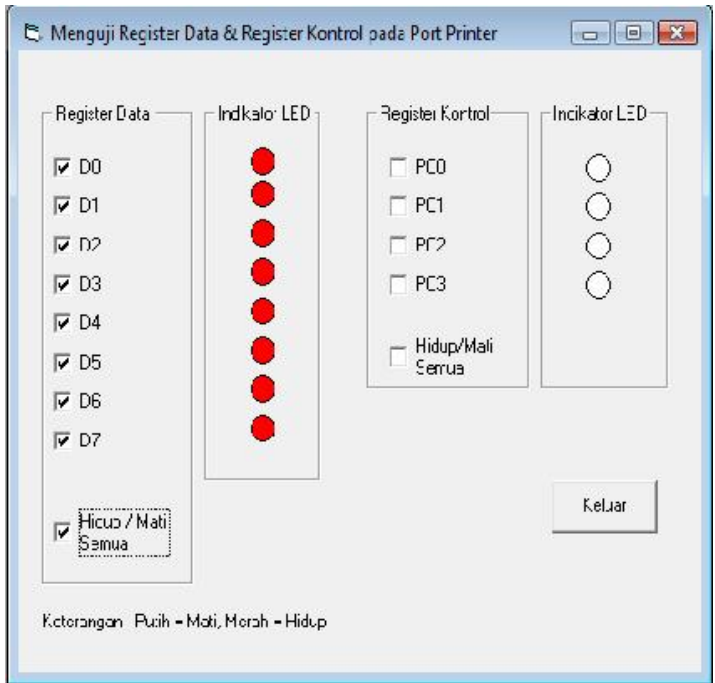

Gambar 3c. Menghidupkan semua LED pada Register Data
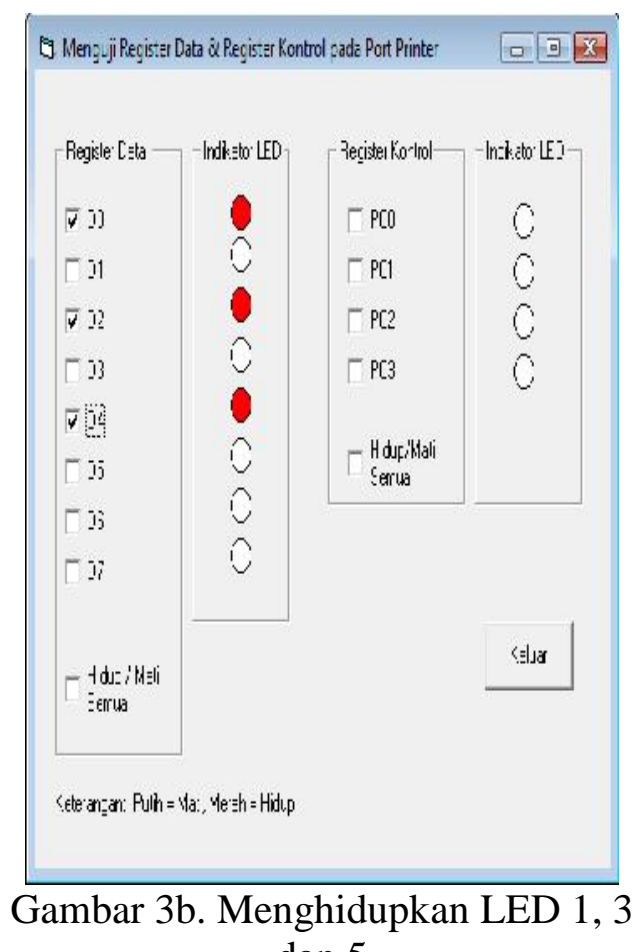
dan 5

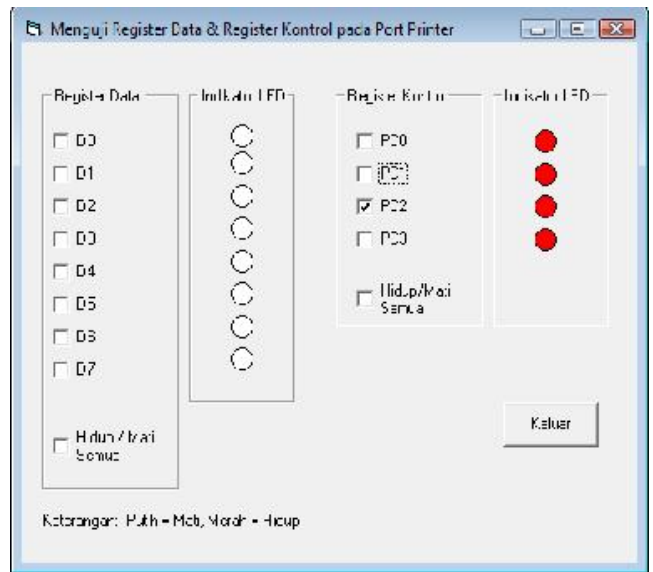

Gambar 3d. Menghidupkan semua LED pada Register Kontrol (PC0,PC1,PC3) bersifat terbalik 


\section{KESIMPULAN}

Berdasarkan hasil pengujian baik perangkat keras maupun perangkat lunak, maka dapat simpulkan seperti berikut:

1. Sifat Register Data adalah dua arah (bi-directional), sehingga dalam aplikasi dapat digunakan sebagai masukan dan keluaran

2. Sifat Register Kontrol adalah searah, dan perlu diperhatikan posisi bit yang bersifat Normal dan Terbalik.

3. Dalam pemrograman akses port menggunakan instruksi PortOut [Alamat, data] untuk mengirimkan data. Sedangkan untuk membaca data digunakan instruksi PortIn [Alamat].

4. Agar computer dapat mengenal port parallel, copy-kan file io.dll pada folder C:IWindowsiSystem dan tambahkan module seperti berikut:

a. Mengirim data

Public Declare Sub PortOut Lib "io.dll" _ (ByVal Port As Integer, ByVal Data As Byte)

b. Membaca Data

Public Declare Function PortIn Lib "io.dll" _ (ByVal Port As Integer) As Byte
DAFTAR PUSTAKA

Agus Sadono (2004), “M emanfaatkan Port Printer Komputer menggunakan Delphi", Semarang: Presisi Offset Afgianto Eko Putra (2009), "Akses Port Menggunakan Visual Basic", Jakarta : Elexmedia Komputindo. 